\title{
Analysis of the effects of agricultural land use change on rural environment and landscape through historical cartography and GIS tools
}

\author{
Dina Statuto, Giuseppe Cillis, Pietro Picuno \\ School of Agriculture, Forestry, Food and Environmental Sciences, University of Basilicata, \\ Potenza, Italy
}

\begin{abstract}
The human activities and the social and economic transformations occurred during the last century led modifications in the agro-forestry areas. This paper shows a study case study in which the dynamics of land use are analysed using a geographic information system applied to historical maps in order to evaluate the consequences of these land transformations over the last 179 years on the rural environment and landscape. The use of three-dimensional reconstructions, obtained through the creation of different digital terrain model, has allowed to appreciate the landscape modifications, in term of morphological and vegetation variation, determining its aesthetic quality. The analysis shows a common dynamic present in many rural areas of Southern Italy, i.e., the increase of agricultural areas replacing forested surfaces in an older period followed by the further phenomenon of spontaneous re-naturalisation of many of these areas, due to the abandonment of extensive cultivated areas. Moreover, through comparison with historical documents, it was possible to analyse how the agricultural activities influenced the quality of the forest ecosystem. The methodology employed in this study allows a detailed analysis of the processes that occurred in different rural context and the creation of appropriate tools for sustainable land management.
\end{abstract}

Correspondence: Dina Statuto, School of Agriculture, Forestry, Food and Environmental Sciences (SAFE), University of Basilicata, viale dell'Ateneo Lucano 10, 85100 Potenza, Italy.

Tel.: +39.329.8439319.

E-mail: dina.statuto@unibas.it

Key words: Rural land; geographic information system; historical maps; image processing techniques; landscape analysis.

Contributions: the authors contributed equally.

Conflict of interests: the authors declare no potential conflict of interests.

Received for publication: 27 April 2015.

Accepted for publication: 19 December 2015.

(C) Copyright D. Statuto et al., 2016

Licensee PAGEPress, Italy

Journal of Agricultural Engineering 2016; XLVII:468

doi:10.4081/jae.2016.468

This article is distributed under the terms of the Creative Commons Attribution Noncommercial License (by-nc 4.0) which permits any noncommercial use, distribution, and reproduction in any medium, provided the original author(s) and source are credited.

\section{Introduction}

The modern society increasingly utilises the rural land in a great variety of ways and for many purposes, so highly valued landscapes that developed during centuries, vanish or are completely transformed within a limited number of years (Vos and Meekes, 1999). During the last decades, changes in land use and management have led to the degradation of many cultural landscapes in European rural areas with relevant consequences for local populations, landscape functionality and the maintenance of ecosystem services (Rescia et al., 2010). The analysis of the rural land modification, as well as its environment and landscape, is important in order to understand the profound transformations connected with the human intervention and natural events (Statuto et al., 2014). An analysis of land-use and land cover changes is fundamental for the understanding of numerous social, economic and environmental problems and can be carried out rapidly, using either cartographic or census data (Pelorosso et al., 2009). Multi-temporal analysis of land, with the support of geographic information system (GIS) and historical document, is a very important tool for monitoring landscape diversity and for investigating changes in vegetation and landscape structure (Yeh and Huang, 2009; Statuto et al., 2013). Some specific landscape analysis, conducted by Capobianco et al. (2004) using a GIS approach have shown the positive results of applied agronomic practices in terms of $\mathrm{CO}_{2}$ fixation; through the implementation of a digital terrain model (DTM) enriched with the drape of land cover pictures, the authors evaluated the morphological and vegetation variations of agro-forestry landscape. The digitalisation of historical cartography, enabling the analysis of the natural and anthropic changes of rural land, allows the possibilities to understand the evolution of landscape changes, in order to be able to account the susceptibility of spaces, considering territorial transformations and looking more closely at spatial and contextual specifics; this is essential for a correct spatial planning (Scheeberger et al., 2007). Analysing land use changes generally requires an integrated approach that considers multiple disciplines, data sources and methodological constructs (Mutoko et al., 2014). Real and useful tools for appropriate planning of agricultural land by politicians and planners that should take into account also environmental aspects were only recently developed.

The relationship among agriculture, ecosystems and environment were proposed by some authors (Tassinari, 2006; Adinarayana et al., 2006) as new contributions to territory and landscape planning and management. Many of the processes of land evolution and transformation are almost imperceptible when viewed over shorter periods, but in the long term they may well lead to changes in the carrying capacity, water balance, and usability of the landscape (Haase et al., 2007). Rural, forestry and aesthetic changes may affect different components of territory, and modifications of rural areas are certainly an important variable in the planning of landscape. Changes in land use and climate are two major global developments projected for the future (Yan et al., 2013). During the past two decades three phenomena are re-drawing 
the configuration of rural areas: the mechanisation, the accelerating demise of traditional rural life and an increase in the mobility of individuals (Domon, 2011). In fact, in many developed countries, a particular land-cover change pattern has taken place: plains are being increasingly utilised for human activities, while mountain areas are being abandoned and are undergoing natural reforestation processes (Ales et al., 1992; García-Ruiz et al., 1996; Debussche et al., 1999; MacDonald et al., 2000; Santos, 2000; Lambin et al., 2003). These generalised patterns can have significant impacts on biodiversity distribution and conservation (Ales et al., 1992; Covas and Blondel, 1998).

Among others, land use change influences in particular the local water balance (Fohrer et al., 2001). The impact of land use change on the annual water balance was relatively small due to compensating effects in a complex catchment, and the decrease of forest due to a grassland bonus amplifies the peak flow rate and thus increases the risk of flooding. Also Öztürk et al. (2013) showed such as land use dynamics can have a significant impact on watershed hydrology: the results of this study, in fact, demonstrate that the water budget is most sensitive to variations in precipitation and conversion between forest and agricultural lands, but it is less sensitive to the type of forest stands.

Land-use and land-cover change has long been a key topic in Landscape Ecology. In particular, forest fragmentation is known to affect species composition and diversity, thus threatening the integrity of forest habitats (Geri et al., 2010). Image processing techniques and landscape pattern metrics were applied to quantify the changes in forest cover patterns, while appropriate statistical descriptors were adopted to investigate the relationship between land-cover changes and topographical factors.

The visual impact of some agricultural practices on the landscape has been recently considered. Visual impact on landscape quality is concerned with physical changes introduced into a site by a new development activity (Amir and Gidalizon, 1990). Land abandonment and the loss of traditional land-use systems are widespread in most of Mediterranean Europe. In the mid 1950s an increase of forested area in relation to the loss of semi-natural and agricultural area was observed in several Mediterranean countries such as Spain, Italy and Portugal, this situation occurred mainly in mountainous areas with a significant loss of agro-forestry ecosystems and the homogenisation of landscape patterns (Jones et al., 2011; Tomaz et al., 2013). In the Mediterranean mountains and hills, spontaneous reforestation occurred in the last fifty years, this process was triggered by depopulation and cessation of traditional farming (Bracchetti et al., 2012). This disappearance of Mediterranean and European cultural landscapes is considered as a relevant problem for biodiversity conservation (Mazzoleni et al., 2004) and for a loss of cultural heritage elements (Van Eetvelde and Antrop, 2004).

Many systems for the rational collection and analysis of forestry and agricultural land data are available. Thanks to them it is possible to know in greater detail the characteristics of the area, and to assess the difference occurred during the years, so understanding the land use variation on time. GIS-based techniques, image processing, remote sensing and other new technologies for the survey, planning and management of land evolution are now enabling for a more accurate analysis of rural landscape and environment (Capobianco et al., 2004; Massoud et al., 2004; Picuno et al., 2011). In particular, GIS are excellent tools for landscape modelling and three-dimensional analysis. They allow an easy digitalisation of geographical information and coverage structure, as well as facilitating graphical representation (Hernández et al., 2004). A GIS approach for territorial analysis, comparing historical maps with contemporary maps, is necessary to understand the landscape dynamic (San-Antonio-Gomez et al., 2014). The advent of high spatial resolution satellite imagery and more advanced image processing and GIS technologies, has resulted in a switch to more routine and consistent monitoring and modelling of land use/land cover patterns. Remote-sensing has been widely used in updating land use/cover maps. Land use/cover mapping has become one of the most important applications of remote sensing (Lo and Choi, 2004). Remote sensing data are very useful because of their synoptic view, repetitive coverage and real-time data acquisition. The digital data in the form of satellite imageries, therefore, enable to accurately compute various land cover/land use categories and help in maintaining the spatial data infrastructure, which is very essential for monitoring urban expansion and land use studies (Mukherjee, 1987, Hegazy et al., 2015). In contrast to modern maps, historical hand-drawn maps present even more formidable challenges to automated data capture and object recognition, owing to the significantly lower graphical quality of the production and printing technologies of the time (Leyk et al., 2006). Nevertheless, such documents contain valuable information about the historical landscape and are needed for GIS-based land cover change analysis. When an historical support, like cadastral registers, old maps, etc. (Bender et al., 2005a, 2005b) could be available, an analysis of the evolution during time of rural landscape may be also possible. In landscape studies, historical maps have been used for a variety of purposes, such as analysing changes in land use or reconstructing landscape and vegetation transitions over time (Simpson et al., 1994).

In the framework depicted above, which describes all aspect characterising the study area and the rural land investigated, we decided to analyse, in a specific way, the land use dynamics and topographic changes from 1829 to 2008 by a comparative examination of different historical cartographic supports and more recent maps, in order to obtain conclusions about the rural landscape changes, their connection to human activities-agricultural production, in particular, and natural events - and the consequences for the rural land. This analysis was conducted in order to enable policy decisions that support sustainable development, to acknowledge present and future development trends and their potential economic, social and ecological impacts (Gutzler et al., 2015).

\section{Materials and methods}

\section{Study area}

The study area is located in Southern Italy, in Basilicata region. It spans about $18 \mathrm{~km}^{2}$, covering one part of the Forenza municipality ( $40^{\circ}$ 47' 57 " N, 15 ${ }^{\circ} 51^{\prime} 39,4$ " E, datum WGS84) (Figure 1). The area embodies the territory represented by an historical cartographic map-dating year 1829 that was used to assess the land use change. It is characterised by different watersheds that flow into the Bradano river, an hilly topography often characterised by high slope, forest and natural land. The altitude of the area ranges between 92 and $450 \mathrm{~m}$ a.s.l. The soil structure has determined the various topography of this area, which has influenced the socio-economic context and agricultural activities. Moreover the wooded area, superficial water resources and ground waters have contributed to the conservation of biodiversity. Except for land use, the variables that are required for monthly groundwater recharge rates and monthly groundwater nitrate loading (Li, 2014) are: monthly precipitation, temperature, evapotranspiration and soil types are required variables. Considering the termo-pluviometric data of the weather station located in Forenza, the annual rainfall, in average, is $660 \mathrm{~mm}$ (Hydrological Annals of Ministry), distributed into 86 rainy days with higher values during autumn and winter. The seasonal distribution of rainfall, with a minimum during the summer (July and August), shows a characteristic trend of the Mediterranean climate. 
The mean annual temperature is $12.8^{\circ} \mathrm{C}$, the average monthly temperature is lowest during January with $3.4^{\circ} \mathrm{C}$ and the hottest month is August which recorded a monthly average of $22.8^{\circ} \mathrm{C}$. The soils are characterised by a quartz arenite with clay (Stigliano's Sandstone) and a formation with sandstones and limestones (Serra Palazzo's Formation). The terrains are generally permeable, highly leached with an abundance of siliceous sandstone. Due to the high permeability and the composition, these soils are poor in organic matter, nitrogen and phosphorus with poor results in the capacity of water retention.

The study area is a part of the hydrographic basin of the Bradano river, that crosses the area from north-west to south-east for $6.5 \mathrm{~km}$; after $2 \mathrm{~km}$ it flows-out into Acerenza's dam and then continues its course towards the Jonian Sea. Bradano is one of the major rivers of Basilicata Region, its flow rate is totally dependent on rainfall, in fact river bed is often dry during the summer season. The river course has not been modified by human activities, except some works made to regulate the water flow close to a new road under construction.

\section{Vegetation}

The forest is located in the San Giuliano area. The geolithological, orographic and morphological variability of this study area has created some different microclimatic zones, which allow the development of different vegetal species and related ecosystems. The characteristics of the forestall coenoses are typical of the phytoclimatic area Castanetum (De Philippis, 1937) and Quercus-Tilia-Acer-mixed deciduous forestbelt of Schmid.

At lower altitudes the vegetation characteristics are similar to those of the Mediterranean basin, with those at higher altitudes of the mountain and sub-mountain belt.

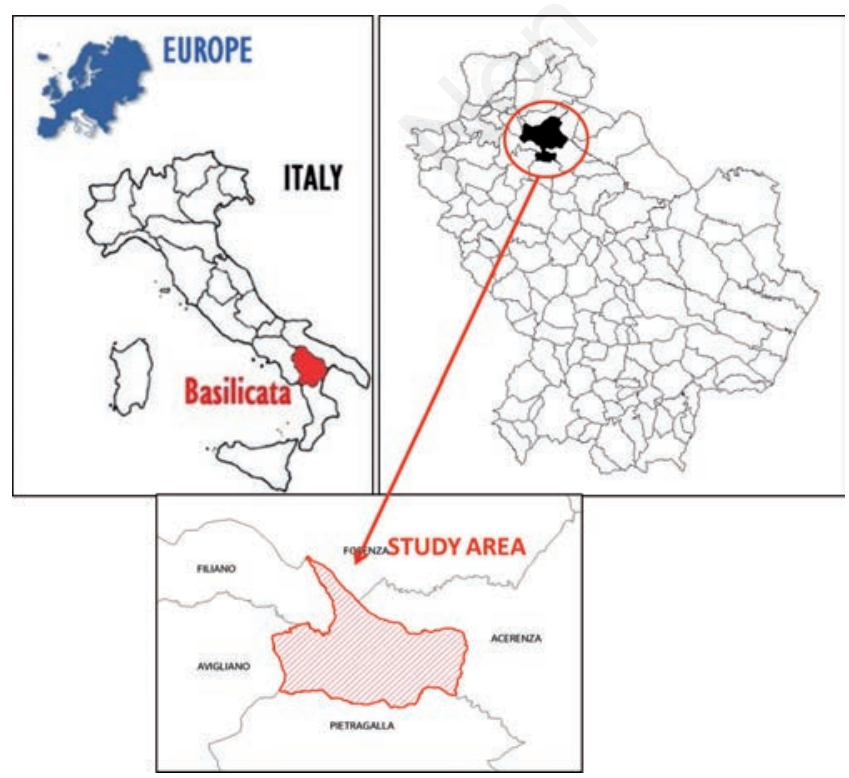

Figure 1. Map of the study area within the Basilicata Region.
Forests are mostly dominated by deciduous oak wood (mesophile and meso-xerophile), while there are some conifers into an artificially reforested area (Pinus nigra J.F. Arnold, Cupressus sempervirens L., Cupressus lusitanica Mill.).

Phytosociological system for classifying community of study area is defined by Aita et al. (1978). This vegetal association (Physospermo verticillati-Quercetum cerris) is exclusive of Basilicata's Region Apennines and is dominated by Turkey oak (Quercus cerris L.). The herbaceous layer is very rich in species; it allows the penetration of a considerable amount of light.

\section{The cartography}

Land use change and geographical reconstruction of landscape were carried-out over a period of 179 years in four time steps: years 1829, 1876,1955 and 2008. It was examined the specific cartography for each time, with the aim to create different base maps that were analysed within a GIS-approach. The historical maps were firstly scanned, imported and georeferenced into a GIS system.

Three different aspects should be evaluated: topographic accuracy, chronometric accuracy and planimetric completeness (Blakemore and Harley, 1980). The first aspect indicates the quantity and quality of information about landscape objects. Each map contains only a selection of geographic features that are selected and symbolised by the cartographer according to the objective of the map. Then it is necessary to consider whether the map depicts all features of a certain class, and how accurately the cartographer classified the features thematically (Laxton, 1976). The second aspect refers to the dating of the map as a physical artifact (by watermark analyses or other techniques), and the dating of the information contained in the map. Dating the age of map

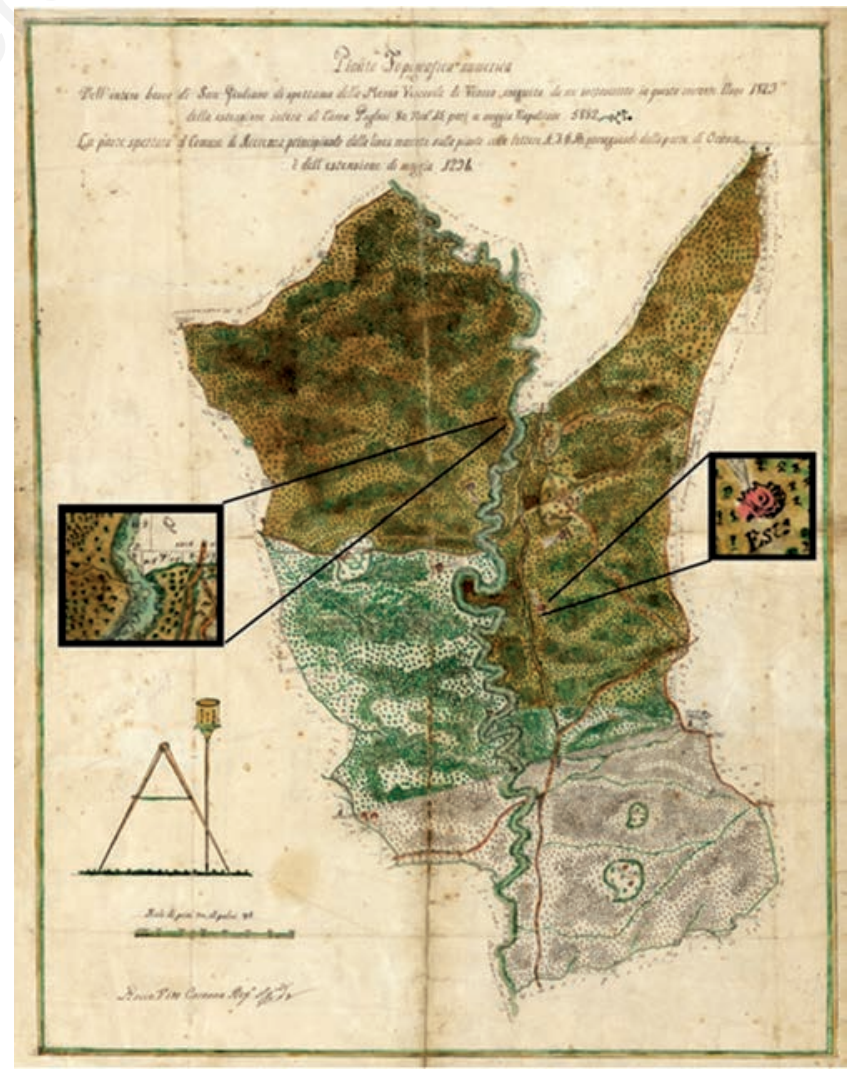

Figure 2. Historical map of 1829 and land use symbols. 
information is often difficult, as the production or the revision of a map commonly takes several years. The third aspect is the planimetric completeness (or geometric accuracy) (Jenny and Hurni, 2011). The maps from 1829 and 1876 are preserved into the State Archive of Potenza, whilst those from 1955 and 2008 are stored in the archive of the School of Agriculture, Forestry, Food and Environmental Sciences (SAFE), University of Basilicata, Italy.

\section{The 1829 historical map}

The historical map was produced after border disputes in year 1829 by legal experts to solve division of domains. Similar maps were realised in the whole South Italy as a result of the abolition of feudalism. These maps were drawn using legal documents and diplomatic sources, which showed the land use rights, and surveying on the ground (Figure 2).

This historical map was manually drawn and represents part of Forenza municipality (San Giuliano's Wood). It constitutes a complete cartographic support, integrated with thematic information about the land use at that time. In particular, the area was divided into two parts, assigned to the municipalities of Forenza and Acerenza, the division was realised according to land surveying techniques of the period. The author used ink on paper and watercolours to report cartographic toponyms, boundaries and other information about rural landscape elements at that time; the interpretation of the written text and different symbols is the only way to detect the land use because there is no legend. Units of measurement are expressed according to the system in force into the Kingdom of Naples, and the scale corresponds to about 1:12,000. An artistic representation of compass rose displayed map orientation.

The analysis of land use is based on the next described operations: i) chromatic differences between the territory of Forenza and Acerenza municipalities (Black and white range); ii) hydrography is coloured in light blue. The contour lines of river course are jagged and marked by a green colour; they symbolise riparian vegetation (Salix caprea, Salix fragilis, Salix purpurea, Populus alba) and also watersheds; iii) forest is represented as some tree-like symbols irregularly distributed. Different density of pattern is correlated to the type of forest management. In fact, areas with a lower density of symbols represent woods exploited for human activities (pasture and firewood). Moreover, these are not covered by green colour, typical of other forest covers of map: i) the orography is not included in the map because there are not contour lines expressing elevation; ii) road network is pictured into two different ways: main streets are larger, well defined and characterised by specific marks, whilst the small road network is marked by a green colour which symbolises margin vegetation; iii) farms and other rural buildings have been reproduced considering their real aspect; various building types (farms of different sizes, a church, a butcher shop, caves and corrals) can be distinguished indeed.

This map reports, around the farms, the presence of agricultural land, coloured in a yellow colour, and the name of some farm districts. The evaluation through chromatic differences was possible thanks to the comparison of other similar historical maps (same period and surrounding areas), which had a more detailed description. In addition, from historical documents, some useful information were obtained, linked to the realisation of the map. They can be considered as ancillary data, able to better describe the historical situation (Forenza Municipality, 1915).

\section{The 1876 map}

The historical topographic map of 1876 was realised by the Italian Topographic Military Institute (ITMI) to create a complete mapping of the Italian territory after its national unification. Geodetic surveying and topographic evaluation were highly accurate and the ITMI decided to immediately print some drafts using photolithography technique. This cartography consists of 174 sheets and the study area is located into a sheet (Sheet 65, Avigliano, eastern part). The scale of map was 1:50,000 and the altimetry has been represented with contour lines, with an equidistance of $10 \mathrm{~m}$, and elevation of the highest areas. The map gives some information about toponyms, presence of farms and land use (Figure 3).

The forest is represented through a pattern consisting of small circles and its boundaries by a line formed by circles; in this map, areas with a lower density of symbols characterises woods exploited for human activities. Areas without symbols represent the agriculture lands. Flamsteed's projection amended is used in this cartography, the coordinate's origin being at the intersection of the meridian of Naples with the $40^{\text {th }}$ parallel.

\section{The 1955 map}

During the period between 1955 and 1954 the Italian Aeronautics Group carried out, on behalf of the USA Army Map Service and Italian Geographic Military Institute (IGMI), an aero-photogrammetric survey with black and white film on almost the whole Italian territory. For the coverage of the study, two photograms were used. Each of these photos was shot in May with focal length of $152 \mathrm{~mm}$ (Fairchild camera), the size of the photo is $230 \times 230 \mathrm{~mm}$, the flight altitude is around $6000 \mathrm{~m}$, its approximate scale is $1: 33,000$. The quality of the survey allows an accurate assessment of land use.

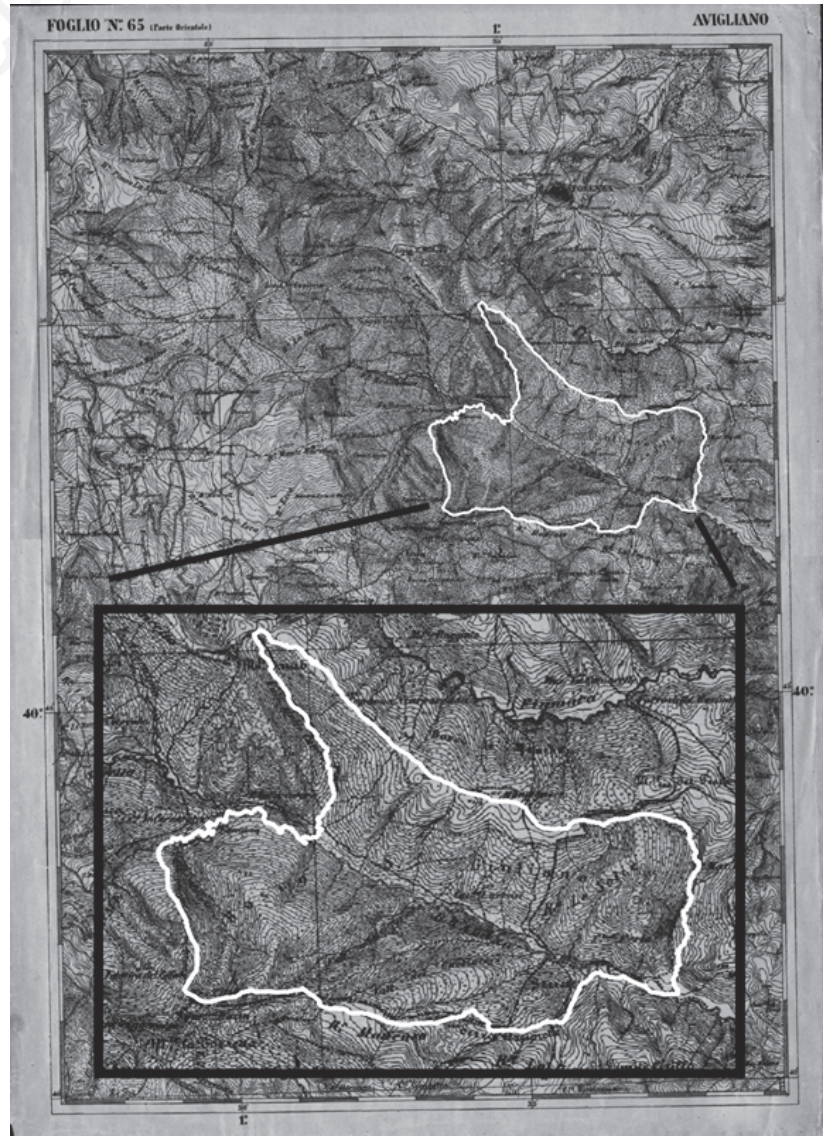

Figure 3. Cartographic map of year 1876 produced by the Italian Topographic Military Institute. 


\section{The 2008 map}

Orthophotos were utilised to determine land use of the year 2008. They combine the image characteristics of a photograph with the geometric qualities of a map; the ground features are displayed in their true position. This allows us the direct measurement of distance, areas, angles and positions (Tortora et al., 2015). The photograms were shot between June and August. Each orthophoto is made up of four RGB visible bands or near infrared with ad average pixel value of $0.5 \mathrm{~m}$. The projection is within the Italian geodetic system Gauss-Boaga - Roma 40.

\section{Historical documents}

The information reported in some historical documents may be useful on the land use analysis; they may also support in map reading, if there is not a legend, and explain some qualitative and quantitative data about historical land use. For this study the historical documents analysed provided information on the main agricultural activities and on the appearance of landscape and environment; so it was possible to trace their evolution. Integrating a GIS methodology to calculate land use change with historical analyses makes possible to identify the dynamics that led to the present landscaping situation.

The information and data should be considered as indicative characteristics because, in some cases, the years do not often correspond precisely with those of the historical maps.

Some documents showing the relevant information for this study were reported: i) statistics of the Kingdom of Naples (De Marco, 1990): the author, reported information about the Forenza municipality. The main agricultural activity consisted in sheep and pigs' livestock; cereal crops covered less than half of the whole territory. Quercus cerris was main tree species, followed by Quercus pubescens; ii) report on usurpation of St. Julian's domain forest (Forenza Municipality, 1915): this report explained the whole process of domain division in the study area, which started in 1829 after the realisation of the map. It reported a lot of information about the condition and value of forests, because these represented an important element of Forenza municipality economy at that time. The economic value is reported; it was very high, due to the presence of roads and, in particular, to the dimensions of trees; iii) historical documents from Forenza's municipality archive: other documentation gives information about Forenza municipality forests and in particular of the San Giuliano forest. Until the early 1900s forest management was not correct and illegal logging of public domains were common. The most frequent forest system was clear-cut with reserves of extensive areas. Documents reported extraordinary logging and tillage into the forest, which was commissioned by the Forenza municipality to solve his financial problems.

\section{Preliminary operations}

The maps were firstly scanned and digitised and, before the analysis with a GIS, the adjustment of the old map is an indispensable step. The map was stretched and rotated with the aim to align as well as possible with a modern reference map or a reference coordinate system. Once the map is geo-rectified, information can be extracted from the map (Jenny and Hurni, 2011). In this analysis, every different temporal map was classified in the same coordinate system (Italian geodetic system Gauss-Boaga - Roma 40). To rectify historical maps (1829-1876) and aerial photos, a sufficient numbers of control points on a georeferenced map were identified (topographic maps of IGMI or ortophoto of year 2008).

In particular, in order to geo-reference the historical map, a first approximated geo-referencing operation was carried out, with the aim to position the map in the area of study. For this first phase, five control points and a first-order polynomial transformation was used. Subsequently, it was performed the real geo-referencing, in which sev- enteen control points - based on the analysis of the river, watersheds and roads - were added. Third-order polynomial transformation was used. The ortho-rectification, after error checking, can be considered acceptable. The same method was used to rectify 1876 and 1955 maps. In the first case good results have been obtained using fourteen control points (some buildings and land elements) that can be considered suitable for the identification of land cover; in the second case, twenty-two control points were considered. Both maps have been transformed with a third-order polynomial.

\section{Data analysis}

With the aim to analyse the evolution of land use in different time step, all maps were converted into data, and each homogeneous parts of area were identified with different categories of land use; the number and features depend on the cartographic base. The land use of the historical maps of 1829 was divided into 5 categories thanks to the interpretation and the integration with historical documents. The same categories have been used to digitise the land use on the map of ITMI. The land use of 1955 and 2008 have been assessed with the same methodology because their cartographic bases are similar; these types of map are more detailed and therefore it is possible to identify 9 categories, for the year 1955, and 11 categories, for the year 2008. To have a more complete view of current land use, it has been carried out a fieldwork to correctly identify the types of land use and locate them through a GPS. The evolution of cartographic information generated an increase of details and therefore the number of land use categories identified. To compare the different land use layer it was necessary to aggregate the different categories into 5 classes.

The most important categories identified in the study area are: i) natural land: includes forest (according to FAO definition) and transitional woodland-shrubs, an afforested land with conifers realised in the 1960 s, transitional woodland-shrubs area (containing shrub or herbaceous vegetation with scattered trees and vegetation formations that may result from the degradation of the forest or a regeneration of the same for re-colonisation of non-forest areas); ii) agricultural land: includes all types of cultivated areas, i.e., arable lands, vineyards, olive groves, permanent crops like orchards, permanent pastures and natural grassland, natural pastures with spontaneous herbaceous vegetation; iii) urbanised area: includes the new and the old farms, buildings and artificially surfaced next to farms. This category includes also the builds to regulate water flow near an under construction road; iv) road network: includes only roads involving a significant surface and with an important traffic flow. Provincial and municipal roads are included; however, all typologies of rural roads are not included; v) river: includes the areal extent that is the bed of the Bradano river and the vegetation present along the river.

For each category, the total area expressed in hectares (ha) and the percentage of its variation over the years was calculated. Road network has been also evaluated in its linear extension, calculating the length in meters (m).

\section{Three-dimensional modelling and image processing}

Through the digital processing of the maps it was possible to reconstruct the three-dimensional shape of the land, thanks to a photo-mosaic procedure and the virtual reconstructions of the land during different time periods. Recently, 3D visualisation has been receiving more attention as a useful tool to understand engineering phenomenon, or to detect important elements that cannot be found in usual simulations. Visualisation in a virtual environment is a useful method that allows people to appreciate archaeological or historical objects through the computer (Kakiuchi and Chikatsu, 2010).

The first step is to acquire altimetry information; within a GIS the 
contour lines from maps of the years 1876, 1955 and 2008 were digitised and extracted. The map of the year 1829 was appropriately correlated to altimetry before year 1876 . Thanks to spatial analysis functions it is possible to create the DTM. Overlapping photographic image, topographic map and other cartographic data allow the realisation of a three-dimensional view, useful to appreciate landscape modification from different viewpoints.

Moreover, through spatial analysis and image processing, using aerial photos dated 1955 an historical reconstruction of the year 1829 landscape was obtained, with a virtual jump of 179 years back, thanks to an ante litteram flight (since at that time airplanes did not exist yet). By doing so, it is possible to appreciate qualitatively, in term of morphological and vegetation variations, the agro-forestry landscape changes, starting from a comparison between three-dimensional reconstructions of the area during different time layers.

\section{Results}

From the superimposition of the different base maps, thanks to GIS technologies and the comparison between historical cartographic supports compared with the current situation, it was possible to identify the different categories of land use.

\section{Land use}

The study area consisted of $57 \%$ natural area, $40.5 \%$ agricultural land, $1.1 \%$ river, $0.9 \%$ road network and $0.1 \%$ built up area in 2008 . The percentage of natural land decreased less intensively from the year 1829 to 1876 , with a reduction of 100 ha $(-4.7 \%)$, and intensively from 1876 to 1955 , with a reduction of 229 ha $(-13.3 \%)$; agricultural land increased from about $31 \%$ in 1829 to 50\% in 1955 (Figures 4 and 5). This trend reversed from 1995 to 2008: the analysis shows in fact a reduction of about 171 ha of agricultural surface, almost counter balanced by an increase of natural land from $48.4 \%$ to $57.4 \%$ (Table 1 ). The main difference occurred, as a widespread trend detected in other different areas of Basilicata region, as a mutual exchange between the areas for agriculture and crops, whose reduction gave more space to the natural area (Tortora et al., 2015).

The territorial extension of rivers decreased from about 41 ha in 1829 to 20 ha in 2008. In particular, analysing each category without aggregation, woodland reduced from about 1211 ha in 1829 to 856 ha in 2008 with a minimum peak in the year 1955 (752 ha).

The surface for different agricultural activities was modified; in the year 1829 , the pastures represented $98 \%$ of the agricultural land and covered $31 \%$ of the study area; on the contrary, from the year 1955 to 2008 arable land (cereals and fodder crops) constituted the $93.6 \%$ and $88.9 \%$ of agricultural land. In 2008 the territory was also covered by olive groves and vineyards (about 23 ha and $15 \mathrm{ha}$ ). The introduction


Figure 4. Land use categories in different periods. 
of these crops since the second half of the last centuries has entailed effects on the landscape visual impact; human activities and agricultural practices have thus influenced the landscape structure, creating a mosaic of different land use categories.

\section{Infrastructures}

The evaluation of infrastructure affects both the road network that the built areas. The surface extension of the road network has been only estimated in 2008, since the other historical maps did not allow the possibility to estimate the area. Therefore, the total lengths have been evaluated in all the analysed time steps. In $2008,0.9 \%$ of study area was crossed by roads (provincial and municipal roads that connect neighbouring towns) with a significant traffic flow; instead the linear extension of these roads was about $14 \mathrm{~km}$.

The total lengths of road network has increased over the years; it passed from about $22 \mathrm{~km}$ in the year 1829 to $69 \mathrm{~km}$ in 2008 , that were exclusively related to agricultural activities (paths and bridleways) until 1955. In year 2008 about $20 \%$ of roads were asphalted.

Regarding buildings and farms present in the study area, the analysis shows an increase in the number and surface. Farm buildings play a central role in the environmental characteristics of agricultural land. Over the centuries they have accompanied the development of the agricultural activities (Picuno, 2012). In year 1829 the buildings were n. 13; they occupied an area of 0.8 ha, whereas in year 2008, 55 buildings occupied an area of 2.1 ha, this value including many abandoned farms.

Table 1. Analysis of land use categories in percentage (\%) and surface (ha).

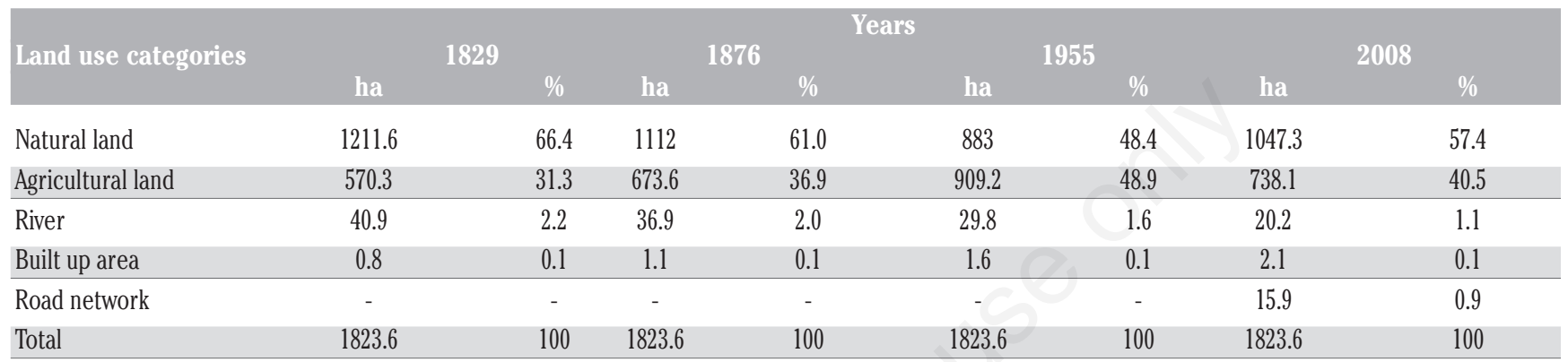
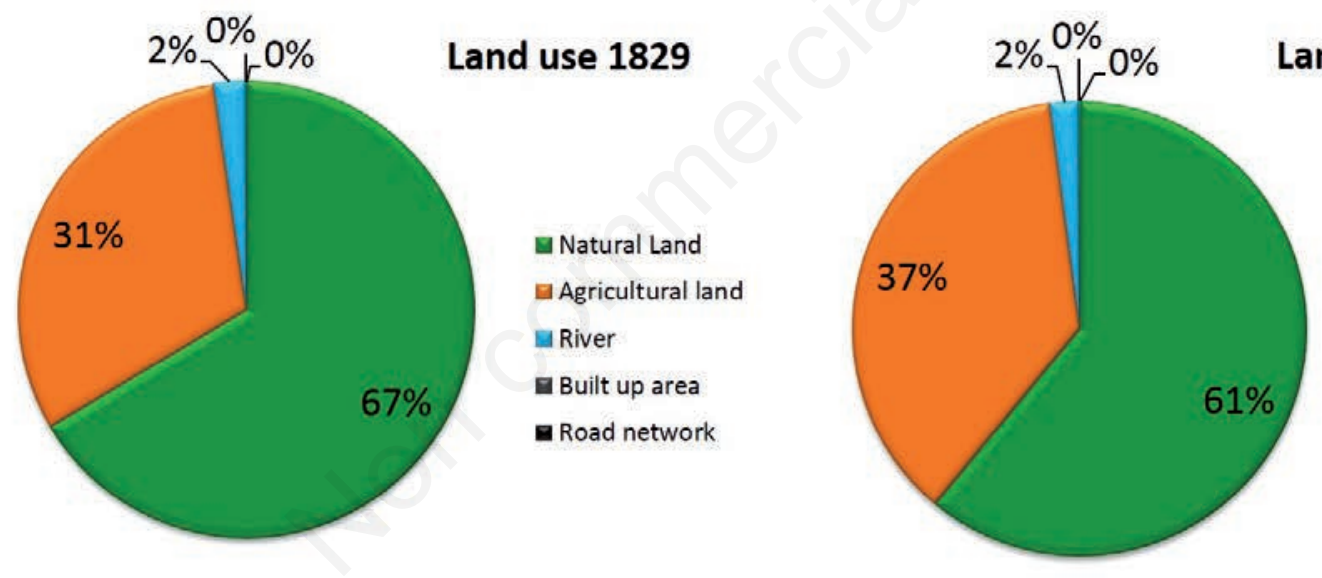

Land Use 1876

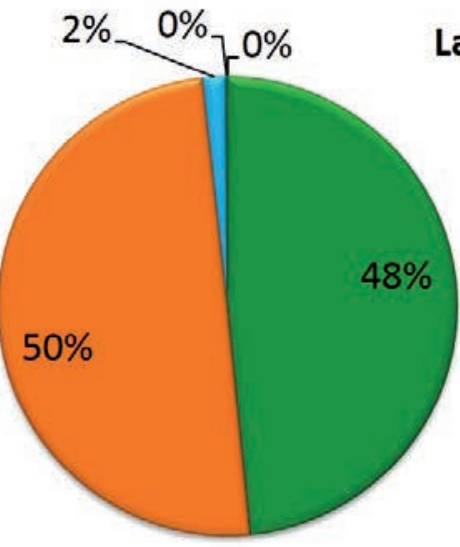

Land Use 1955

Agricultural land

Giver

Built up area

Road network

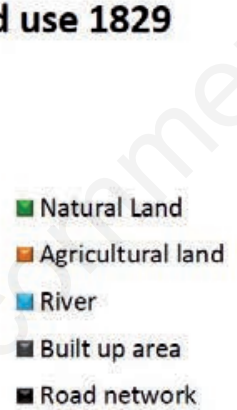

Natural Land

Agricultural land

Giver

Built up area

Road network

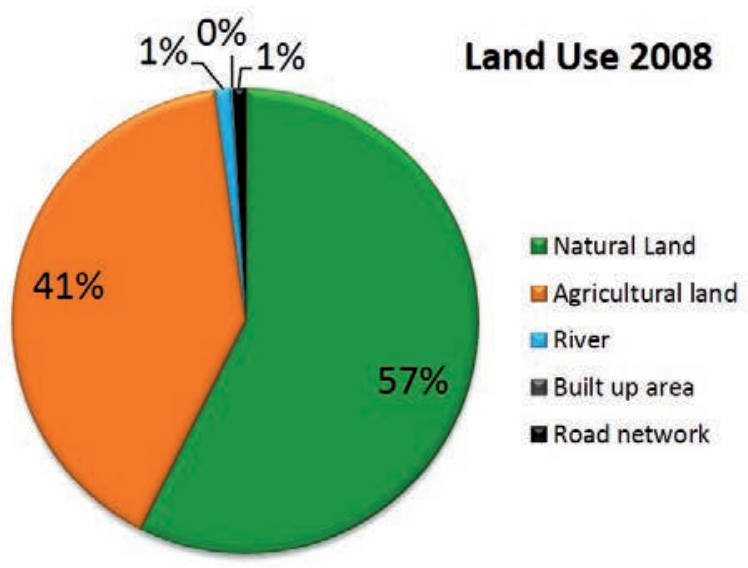

Land Use 2008

Natural Land

agricultural land

Biver

Built up area

日Road network

Figure 5. Analysis of land use categories in different periods. 


\section{Landscape}

Land use maps and DTM may be adequately treated within a GIS to create, through spatial analysis procedures, some three-dimensional views, which may be used to appreciate the morphological and aesthetic landscape variations. The overlapping of different thematic maps provides an additional database, by which it can be possible, a comparison between different years.

Starting from the DTM of years 1876 and 1955 it was possible to reach a slope map (in percentage) classified into 8 classes. These maps have been used to correlate agricultural activities with topography of the study area and, therefore, to identify the reasons that have influenced the landscape variation over the years.

This type of analysis shows that about $90 \%$ of the arable land occupied a surface with a slope less than $25 \%$ (class moderately steep) in the year 1876. Instead in the year 1955 this value decreased to $59 \%$ and then increased again to $78 \%$ in 2008 year.

Figure 6 shows an hypothetical virtual ortophoto in black and white, obtained with a cross comparison between the categories of land use in 1829 and the same type of land cover detected in the aerial photos in 1955 , by using photo mosaic and photo editing processes. Finally, for each year, the cartography base and the other thematic maps on DTM have been overlapped; this process allows the three-dimensional reconstructions of the landscape over the years.

\section{Discussion}

\section{Land use dynamics}

The analysis starts from the situation of land use in 1829; it can be noticed that the landscape of study area at that time was especially characterised by oak wood, in which there were areas with a less forest density canopy, where it was performed the predominant agricultural activity of Forenza municipality at that time: the livestock. The importance of this activity, in particular of sheep livestock, was reported in historical documents and in thematic cartography (Food products map of the Kingdom of Two Sicilies's continental provinces, 1859). Moreover, the arable land was restricted around the farm; it was represented with a corral. The road network was not very extensive and it was limited to a network of paths used for the connection between the neighbouring municipalities and farms. In year 1829, the river was an important element for the agriculture and livestock because some roads were parallel to its course, and its extension was higher than other years. After 47 years, during year 1876, there was an increase of agricultural land due to higher food requirements of the Forenza municipality population, which was gradually increasing. Arable lands were only extended nearby the main road network, and where there was a less slope degree because they were the most easily accessible areas.

Woodlands still covered the most part of the study area but they were starting to become a source of income for the population which carried out some intensive clear-cut (thanks to Bourbon forestry law that allowed a deforestation with the release of 60 seed trees per hectare) and to solve economic problems. Quality of forests, with its high economic value, and some illegal frequent cuts of the best trees are often mentioned in the historical documents.

After the Second World War, the landscape was significantly modified thanks to the general economic rise and some specific reforms for the South of Italy that imposed a resulting radical change in the land management. In fact the land use has been heavily influenced by the land reform (Law of October 21, 1950, no. 841, Regulations for the expropriation, land reclamation, processing and allocation of the peasants's land), having among its objectives the qualitative and quantitative improvement in land use and equity for the farmers (Italian
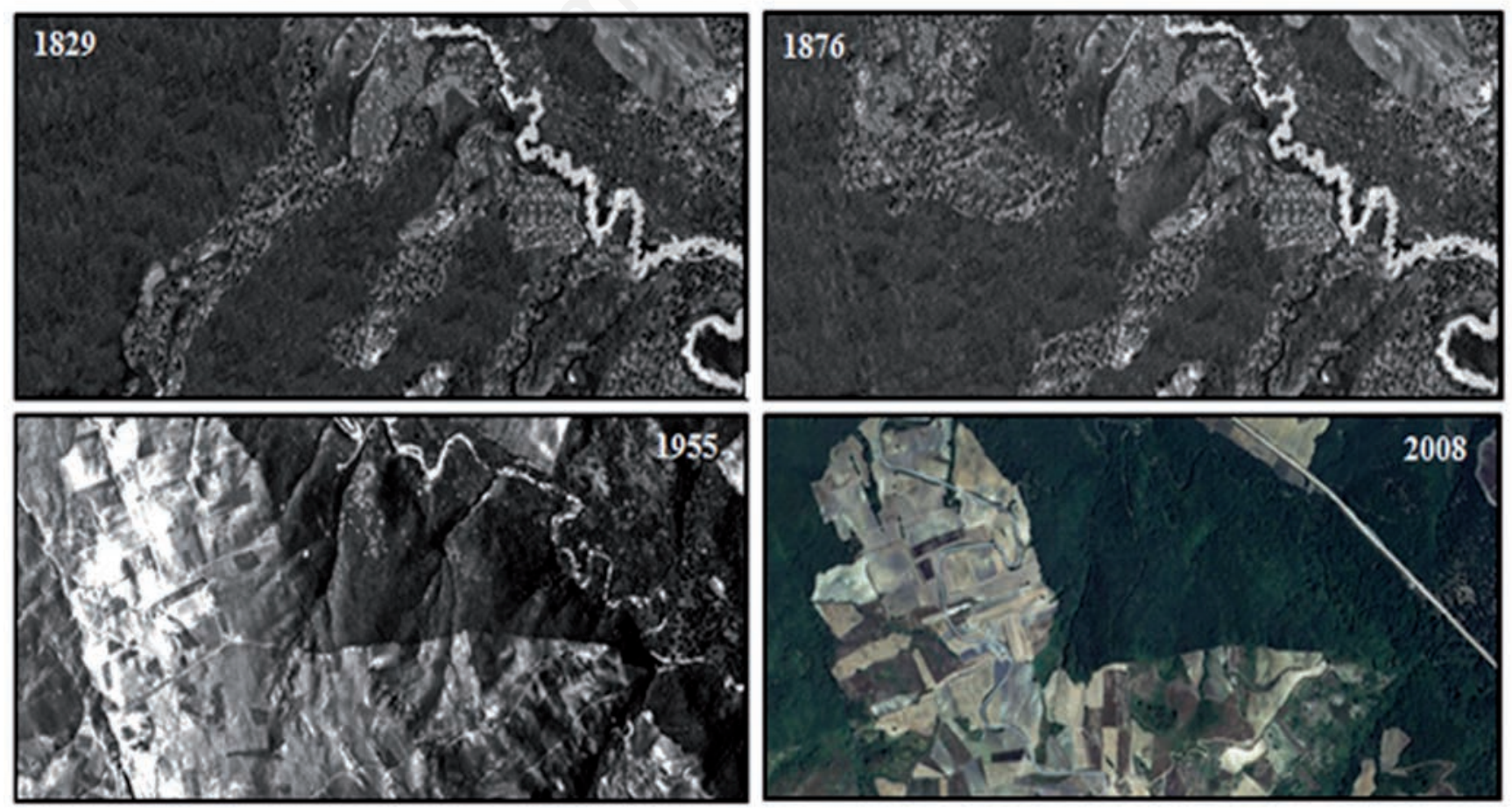

Figure 6. Analysis of land through virtual and recent ortophotos. 
Regulation, 1950). This law proposed, through the forced expropriation to landowners, a free redistribution of arable land to farmers without landed property, and financed works of land transformation with the aim to support land reclamation and irrigation. Consequently there was an increase of arable land and above all of cereal crops which, being more profitable, replaced the pastures. The diffusion of an extensive agriculture, the improvement of cultivation techniques and state financings involved a change in the landscape structure, because marginal and steep areas were cultivated. Consequently, with the increase of agricultural activities, the roads and the buildings were doubled. The current trend, as demonstrated by the analysis of land use in the year 2008 , showed a progressive decrease in the agricultural areas to the benefit natural vegetation that grow up over the years, that has spontaneously covered areas that in the past were cultivated. This phenomenon is steadily increased over the past decades, i.e., with the development of the so-called set-aside regime (EEC Regulation 1272/88) by common agricultural policy to control the overproduction of cereals and other crops, in order to avoid the reduction on agricultural prices (European Commission, 1988; Tortora et al., 2015). Agricultural land use change is often a proximate cause of other changes, but it is not always possible to identify proximate causes for agricultural change itself, except for urbanisation and the development of natural areas (van Vliet et al., 2015).

The road network, compared to previous years, has increased in length over the years and its system improved with the construction of provincial and municipal roads. About 70\% of road network in 2008 is represented by rural viability, which proves that the area was not affected by humans' over-exploitation. The increase of urbanised area was due to the economic well-being and to the construction of new farms in replacement of the old ones, no longer used, or some old buildings have been transformed from small farms into agricultural holdings.

It can be concluded that, combining historical cartographic supports with modern spatial analysis techniques, it was possible to evaluate the vegetation, as well as the land use and the resulting landscape changes that have interested the study area. This investigation considers therefore the variation in time and space, within a specific local context limited to a study area that is predominantly a rural district. The same methodology could be indeed applied within a larger territorial context; in order to assess wider landscape changes occurred over time.

\section{Environment and landscape modifications}

The analysis has allowed making an assessment of the land use evolution, on landscape changes and environmental modifications, during 179 years, that were investigated in terms of vegetation, environmental and visual impact. In 1829, the landscape was dominated by oak wood in which, especially in the area near the farms and the river, the cattle could graze. From an environmental viewpoint, pastures did not cause significant problems because it was not an intensive type (they could be considered as wooded pastures), interesting about $29 \%$ of the study area. Therefore, the forested areas were the main component of landscape, more important than in the years 1955 and 2008, in which woodland covered only about $41 \%$ and $47 \%$ of the area; therefore, the landscape quality was very high as for naturalness, biodiversity and aesthetic quality (Figure 7). The environment and the landscape quality is demonstrated also by the low impact that human activities had on the area: low-intensity agricultural land use, agricultural activities more suitable within the local territorial context and a little surface only affected by rural settlements.

The increase of the populations needs, from an economic and alimentary point of view, had led to the beginning of landscape changes, because the study area was transformed from high naturalness area to agricultural area. From the year 1876 to 1955 , this over-exploitation of the forest resources has led some problems on the landscape and the environment, whit an impact on the current features. Using the threedimensional modelling, it is possible to see that land use changes and deforestation had involved a significant change in the visual quality of rural landscape because the forested areas of 1829 were partly replaced by arable lands.

The environmental impact of this wooded treatment was negative because the clear-cut radically modified the environmental conditions of the cut area: microclimate variations with an increase of extreme temperatures and changes in the hydrological cycle. In fact, this forestry practice caused problems of slope stability. Currently the area is covered by a conifer re-afforestation (40 ha) planned during 1960 s to protect the soil, to reinforce the slopes and to reduce the water runoff in mountainous and hilly areas.

The intensification of agricultural activity reached its peak in 1955 , when half of the land was cultivated with cereals and almost all woods was used, with the exception of high steepness areas.

The last temporal time step analysed shows a further change into landscape structure due to a development of intensive agriculture and European Community policies.

With the replacement of manpower by extensive mechanisation and the use of chemical fertilisers, there was a decrease in traditional land use practices to the benefit of intensive agriculture, and a large number of varieties of plants and breeds of animal have disappeared. As a result, the ancestral equilibrium between agriculture and biodiversity was put at risk. In the World, so far, about $75 \%$ of crop varieties have been lost, and three quarters of global nutrition depend on only 12 plant species and five animals (Tortora et al., 2015). The landscape is enriched with olive groves and vineyards, which in past years, however, were limited to small areas around the farms. The arable lands, still cultivated, are the most accessible areas where costs of production are lower; in fact they are near roads and less steep (87\% of arable land is located on slopes less than $35 \%$ ).

The consequent result of abandonment of agricultural land is a
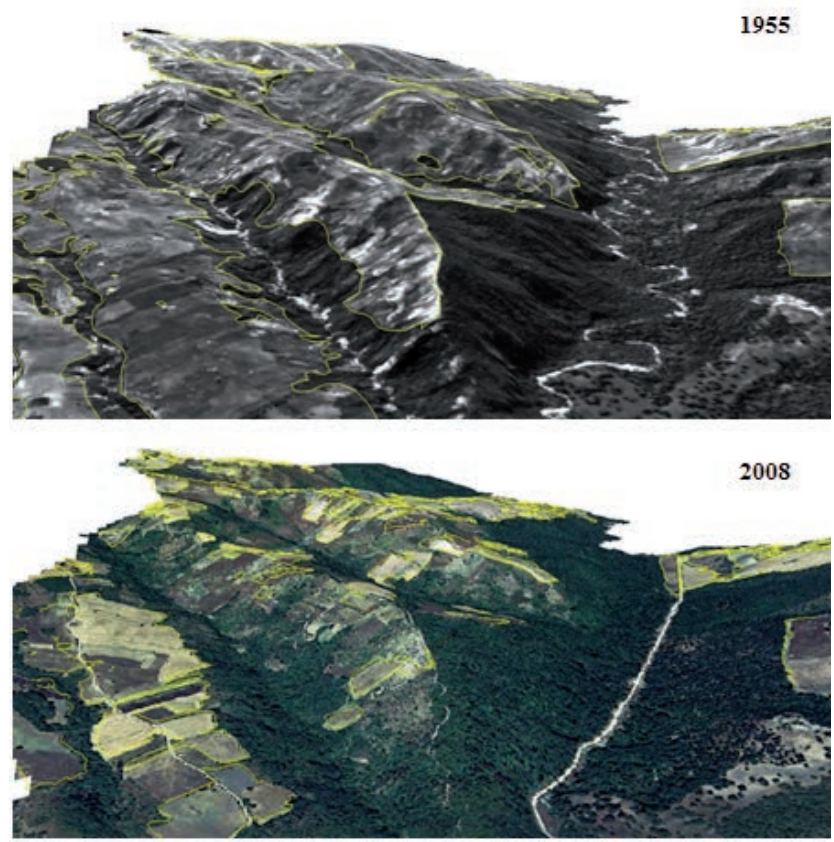

Figure 7. Comparison of three-dimensionally reconstructed land. 
reduction of arable land and a fragmentation of the landscape that becomes more heterogeneous. This phenomenon affected also the forests, which are no longer regularly managed. Regular periodic cutting and a wrong forest management caused an abandoned of forestry due to socioeconomic changes and, in recent decades, to the use of fossil fuel. On the other hand, the land use dynamics led to an increase in naturalness in 2008 .

Currently, woodlands are represented by aged coppice forest (40-60 years old) in which the phyto-sanitary situation is very poor in quality, the forest canopy reaches $80 \%$ of maximum, the growth in height and diameter is reduced and most of the individuals are unstable.

The analysis of 2008 shows that a part of abandoned fields (about $8 \%$ of study area) has been colonised by herbaceous species and shrubs. The wooded area is instead increased especially at the margins of abandoned land, i.e., those with greater slope. The Bradano river surface is also decreased during 179 years of analysis, caused by the growth of riparian vegetation on riverbanks due to a grazing pressure reduction. Moreover, the visual alteration of the landscape is significant along the built area of a future road, which will almost run parallel to this river. Its construction involved the tillage of a forest belt (in some points of $40 \mathrm{~m}$ ). The visual impact is showed by the comparison of digital models of 1955 and 2008 . The conducted analysis would facilitate the transferability of results to other regions and situations (Gutzler et al., 2015).

\section{Conclusions}

In the last decades the land use has simultaneously evolved thanks to the social and economic changes that occurred within different geographical areas. The landscape, the environment and the rural land were subjected to significant and frequently impactful modifications and often they are the subjects for new agricultural and environmental policies. These dynamics, in order to be correctly assessed, require detailed studies, advantaged by the new computer technologies that can be considered as decisive tools for the creation of appropriate instruments for the representation of all the aspects characterising the agro-forestry land. A GIS, for example, allows the implementation of historical models, for quantitative and qualitative studies, to understand the evolution of landscape and rural land, by procedures for the analysis of land use changes with the aim to address correct spatial planning e proper land use management policies.

In this paper the historical analysis shows significant changes occurred in terms of land use, during about two centuries of analysis, due to continuous transformations in landscape patterns and ecosystems functions.

Compared to the situation in the year 1829, the natural area of Forenza municipality decreased, but during the last decades it occurred a common phenomenon widespread in the South of Italy and particularly in the Basilicata region: there-naturalisation of the abandoned agricultural areas. This trend reflects the agricultural reforms and the socio-economic changes, which have also led to the change of some agricultural activities; the cereal crops replaced the pastures with the consequent modification of the landscape structure over the years. The abandonment of arable land is steadily increasing, due to the crisis in the agricultural sector, and it necessarily takes into account this phenomenon in the land management policies, because it can cause social, economic and environmental impacts. Many studies show the consequences of the grassland, pastures and woodland recovery after land abandonment. From the ecological point of view, this trend has a lot of positive impacts on the environment (Tasser et al., 2007), e.g., lowered inputs of pesticides, fertilisers and water yields (Gafura et al., 2003), higher carbon sequestration (Wessman, 1992), more stable soils (Tasser et al., 2003) and clean water (Hunsaker and Levine, 1995). On the other hand, the major problems related to this phenomenon have been identified from Banayas et al. (2007): biodiversity loss, increase of fire frequency and intensity, soil erosion and desertification, loss of cultural and/or aesthetic values, reduction of landscape diversity and reduction of water provision. Erosion results in the significant redistribution of soil in agricultural landscapes affecting soil productivity and agro-ecosystem functioning (Helgason et al., 2014).

The impact of these factors depends on the territory conditions; it is not equally significant in all geographic regions. In order to make a correct evaluation, it is important to contextualise the impacts in relation to soil, to the dynamics of land use and to the socio-economic conditions of the area. This is feasible thanks to GIS-methodologies, able to build specific models, which can be used for the assessment of landscape and environmental changes. The extraordinary properties of representation, offered by these modern information technologies, increase the perception of the study areas and improve the informational aspects and the opportunities of visual simulation of the land use evolution. For the process of abandonment, further studies are required, in order to evaluate risks and to develop a more sustainable land management.

The use of this multidisciplinary approach, based on the historical maps, historical documentation and modern cartographic base, allowed to understand the landscape evolution, the possible future trend, through its principal environmental and socio-economic components, in order to address proper land use policies and guidelines for sustainable land management.

\section{References}

Adinarayana J., Laurenson M., Ninomiya S. 2006. Web-based decision support system for rural land use planning - WebLUP - a prototype. Agric. Engine. Int. CIGR Ej. 8:IT 05005.

Aita L., Corbetta F., Orsino F. 1978. Osservazioni fitosociologiche sulla vegetazione forestale dell'Appennino Lucano CentroSettentrionale. 1. Le Cerrete. Archiv. Bot. Biogeogr. Ital. 53:97-130.

Ales R.F., Martin A., Ortega F., Ales E. 1992. Recent changes in landscape structure and function in a Mediterranean region of SW Spain (1950-1984). Landscape Ecol. 7:3-18.

Amir S., Gidalizon E. 1990. Expert based method for the evaluation of visual absorption capacity of the landscape. J. Environ. Manage. 30:251-63.

Banayas J.M.R., Martins A., Nicolau J.M., Schulz J.J. 2007. Abandonment of agricultural land: an overview of drivers and consequences. Perspect. Agric. Vet. Sci. Nutr. Nat. Res. 57:1-14.

Bender 0., Boehmer H.J., Jens D., Schumacher K.P. 2005a. Analysis of land-use change in a sector of Upper Franconia (Bavaria, Germany) since 1850 using land register records. Landscape Ecol. 20:149-63.

Bender 0., Boehmer H.J., Jens D., Schumacher K.P. 2005b. Using GIS to analyse longterm cultural landscape change in Southern Germany. Landscape Urban Plan. 70:111-25.

Blakemore M.J., Harley J.B. 1980. Concepts in the history of cartography. A review and perspective. Cartographica 17:1-120.

Bracchetti L., Carotenuto L., Catorci A. 2012. Land-cover changes in a remote area of central Apennines (Italy) and management directions. Landscape Urban Plan. 104:157-70.

Capobianco R. L., Tortora A., Picuno P. 2004. Analysis of rural land, environment and landscape through spatial modelling and image processing techniques of historical cartography. Riv. Ing. Agr. 35:71-7. 
Covas R., Blondel J. 1998. Biogeography and history of the Mediterranean bird fauna. Ibis 140:395-407.

De Marco D. 1990. La statistica del Regno di Napoli nel 1811 - Volume III (1900), Accademia Naz. dei Lincei, Roma, Italy, pp 24-25, 54-59, 228-233, 474-477.

De Philippis A. 1937. Classificazione ed indici del clima in rapporto alla vegetazione forestale italiana. Società Botanica Italiana, Firenze, Italy.

Debussche M., Lepart J., Dervieux A. 1999. Mediterranean landscape changes: evidence from old postcards. Global Ecol. Biogeogr. 8:3-15.

Domon G. 2011. Landscape as resource: consequences, challenges and opportunities for rural development. Landscape Urban Plan. 100:338-40.

European Commission. 1988. Commission Regulation (EEC) No 1272/88 of 29 April 1988 laying down detailed rules for applying the set-aside incentive scheme for arable land. In: Official Journal L 121, 11/5/1988, pp 36-40.

Fohrer N., Hayerkamp S., Eckhardt K., Frede H.G. 2001. Hydrologic response to land use changes on the catchment scale. Phys. Chem. Earth Part B Hydrol. Oceans Atmos. 26:577-82.

Forenza Municipality. 1915. Relazione sulle usurpazioni del bosco demaniale di San Giuliano. Stab. Tipografico "Fulgur", Potenza, Italy.

Gafura A., Jensen J.R., Borggaard 0.K., Petersen L. 2003. Runoff and losses of soil nutrients from small watersheds under shifting cultivation (Jhum) in the Chittagong Hill Tracts of Bangladesh. J. Hydrol. 274:30-46.

García-Ruiz J.M., Lasanta T., Ruiz-Flano P., Ortigosa L., White S., Gonzales C., Martì, C. 1996. Land-use changes and sustainable development in mountain areas: a case study in the Spanish Pyrenees. Landscape Ecol. 11:267-77.

Geri F., Rocchini D., Chiarucci A. 2010. Landscape metrics and topographical determinants of large-scale forest dynamics in a Mediterranean landscape. Landscape Urban Plan 95:46-53.

Gutzler C., Helming K., Balla D., Dannowski R., Deumlich D., Glemnitz M., Knierim A., Mirschel W., Nendel C., Paul C., Sieber S., Stachow U., Starick A., Wieland R., Wurbs A., Zander P. 2015. Agricultural land use changes - a scenario-based sustainability impact assessment for Brandenburg, Germany. Ecol. Indicators 48:505-17.

Haase D., Walz U., Neubert M., Rosenberg M. 2007. Changes to Central European landscapes - Analysing historical maps to approach current environmental issues, examples from Saxony, Central Germany. Land Use Policy 24:248-63.

Hegazy I.R., Kaloop M.R. 2015. Monitoring urban growth and land use change detection with GIS and remote sensing techniques in Daqahlia governorate Egypt. Int. J. Sustain. Built Environ. 4:117-24.

Helgason B.L., Konschuh H.J., Bedard-Haughn A., VandenBygaart A.J. 2014. Microbial distribution in an eroded landscape: Buried A horizons support abundant and unique communities. Agric. Ecosyst. Environ. 196:94-102.

Hernández J., García L., Ayuga F. 2004. Integration methodologies for visual impact assessment of rural buildings by geographic information systems. Biosyst. Eng. 88:255-63.

Hunsaker C.T., Levine D.A. 1995. Hierarchical approaches to the study of water quality in rivers. Bioscence 45:193-203.

Italian Regulation. 1950. Legge del 21 ottobre 1950, n. 841. Norme per la espropriazione, bonifica, trasformazione ed assegnazione dei terreni ai contadini. In: G.U. no. 249, 28/10/1950. Available from: http:/www.ismea.it/flex/AppData/Redational/Normative/199904220 00100067.pdf

Jenny B., Hurni L. 2011. Studying cartographic heritage: Analysis and visualization of geometric distortions. Comput. Graph. 35:402-11.

Jones N., Graaff J., Rodrigo I., Duarte F. 2011. Historical review of land use changes in Portugal (before and after EU integration in 1986) and their implications for land degradation and conservation, with a focus on Centro and Alentejo regions. Appl. Geogr. 31:1036-48.

Kakiuchi T., Chikatsu H. 2010. Reconstruction and visualization of original landscape on reverse mapping. Int. Archiv. Photogram. Remote Sens. Spatial Inf. Sci. 38:311-5.

Lambin E.F., Geist H.J., Lepers E. 2003. Dynamics of land use and landcover change in tropical regions. Annu. Rev. Environ. Resour. 28:205-41.

Laxton P. 1976. The Geodetic and topographical evaluation of English county maps, 1740-1840. Cartographic J. 13:37-54.

Leyk S., Boesch R., Weibel R. 2006. Saliency and semantic processing: extract-ing forest cover from historical topographic maps. Pattern Recognit. 39:953-68.

Lo C.P., Choi J. 2004. A hybrid approach to urban land use/cover mapping using Landsat 7 enhanced thematic mapper plus (ETM+) images. Inter. J. Rem. Sen. 25:2687-700.

MacDonald D., Crabtree J.R., Wiesinger G., Dax T., Stamou N., Fleury P., GutierrexLazpita J., Gibon A. 2000. Agriculture abandonment in mountain areas of Europe: environmental consequences and policy response. J. Environ. Manage. 59:47-69.

Massoud M.A., El-Fadel M., Scrimshaw M.D., Lester J.N. 2004. Land use impact on the spatial and seasonal variation of contaminant loads to Abou Ali River and its coastal zone in North Lebanon. Agric. Engine. Int. CIGR J. Sci. Res. Develop. 6:LW 04001.

Mazzoleni S., di Pasquale G., Mulligan M., di Martino P., Rego F. 2004. Recent dynamics of the Mediterranean vegetation and landscape. Wiley \& Sons Ltd., Chichester, UK.

Mukherjee S. 1987. Land use maps for conservation of ecosystems. Geog. Rev. India 3:23-8.

Mutoko M.C., Hein L., Bartholomeus H. 2014. Integrated analysis of land use changes and their impacts on agrarian livelihoods in the western highlands of Kenya. Agric. Syst. 128:1-12.

Öztürk M., Copty N.K., Saysel A.K. 2013. Modeling the impact of land use change on the hydrology of a rural watershed. J. Hydrol. 497:97-109.

Pelorosso R., Leone A., Boccia L. 2009. Land cover and land use change in the Italian central Apennines: a comparison of assessment methods. Appl. Geogr. 29:35-48.

Picuno P. 2012. Vernacular farm buildings in landscape planning: a typological analysis in a southern Italian region. J. Agricult. Engine. 43:130-7.

Picuno P., Tortora A., Capobianco R.L. 2011. Analysis of plasticulture landscapes in Southern Italy through remote sensing and solid modelling. Landscape Urban Plan. 100:45-56.

Rescia A.J., Willaarts A.B., Schmitz M.F., Aguilera P.A. 2010. Changes in land uses and management in two Nature Reserves in Spain: evaluating the social-ecological resilience of cultural landscapes. Landscape Urban Plan. 98:26-35.

San-Antonio-Gómez C., Velilla C., Manzano-Agugliaro F. 2014. Urban and landscape changes through historical maps: the Real Sitio of Aranjuez (1775-2005), a case study. Comput. Environ. Urban Syst. 44:47-58.

Santos C.P. 2000. Succession of breeding bird communities after the abandonment of agricultural fields in southeast, Portugal. Ardeola 47:171-81.

Schneeberger N., Bürgi M., Kienast P.D.F. 2007. Rates of landscape change at the northern fringe of the Swiss Alps: historical and recent tendencies. Landscape Urban Plan. 80:127-36.

Simpson J.W., Boerner R.E.J., DeMers M.N., Berns L.A., Artigas F.J., Silva A. 1994. Forty-eight years of landscape change on two contiguous Ohio landscapes. Landscape Ecol. 9:261-70.

Statuto D., Tortora A., Picuno P. 2013. Analysis of the evolution of landscape and land use in a GIS approach. pp 25-33 in First Int. Symp. 
on Agricultural Engineering - ISAE 2013, session VI, October 4-6, Belgrade, Serbia.

Statuto D., Tortora A., Picuno P. 2014. Spatial modeling and image processing of historical maps for rural landscape planning. In: International Conference of Agricultural Engineering-EurAgEng 2014, 6-10 July, Zurich, Switzerland.

Tasser E., Mader M., Tappeiner U. 2003. Effects of land use in alpine grasslands on the probability of landslides. Basic. Appl. Ecol. 4:271-80.

Tasser E., Walde J., Tappeiner U., Teutsch A., Noggler W. 2007. Land-use changes and natural reforestation in the Eastern Central Alps. Agric. Ecosyst. Environ. 118:115-29.

Tassinari P. 2006. A methodological contribution to landscape design and improvement. Agric. Engine. Int. CIGR Ej. 8:MES 05006.

Tomaz C., Alegria C., Monteiro J.M., Teixeira M.C. 2013. Land cover change and afforestation of marginal and abandoned agricultural land: a 10 years analysis in a Mediterranean region. Forest Ecol. Manage. 308:40-9.

Tortora A., Statuto D., Picuno P. 2015. Rural landscape planning through spatial modelling and image processing of historical maps.
Land Use Policy 42:71-82.

Van Eetvelde V., Antrop M. 2004. Analyzing structural and functional changes of traditional landscapes-two examples from Southern France. Landscape Urban Plan. 67:79-95.

Van Vliet J., de Groot H.L.F., Rietveld P., Verburg P.H. 2015. Manifestations and underlying drivers of agricultural land use change in Europe. Landscape Urban Plan. 133:24-36.

Vos W., Meekes H. 1999. Trends in European cultural landscape development: perspectives for a sustainable future. Landscape Urban Plan. 46:3-14.

Wessman C.A. 1992. Spatial scales and global changes: bridging the gap from plots to GCM grid cells. Annu. Rev. Ecol. Syst. 23:175-200.

Yan D., Schneider U.A., Schmid E., Huang H.Q., Pan L., Dilly 0. 2013. Interactions between land use change, regional development, and climate change in the Poyang Lake district from 1985 to 2035. Agric. Syst. 119:10-21.

Yeh C.T., Huang S.L. 2009. Investigating spatiotemporal patterns of landscape diversity in response to urbanization. Landscape Urban Plan. 93:151-62. 